\title{
Status of the nuclear measurement stations for the process control of spent fuel reprocessing at AREVA NC/La Hague
}

\author{
Cyrille Eleon, Christian Passard, Nicolas Hupont, Nicolas Estre, Olivier Gueton, François Brunner, \\ Gabriele Grassi, Marc Batifol, Philippe Doumerc, Thierry Dupuy, Benjamin Battel, and \\ Jean Christophe Vandamme
}

\begin{abstract}
Nuclear measurements are used at AREVA NC/La Hague for the monitoring of spent fuel reprocessing [1]. The process control is based on gamma-ray spectrometry, passive neutron counting and active neutron interrogation, and gamma transmission measurements. The main objectives are criticalitysafety, online process monitoring, and the determination of the residual fissile mass and activities in the metallic waste remaining after fuel shearing and dissolution (empty hulls, grids, end pieces), which are put in radioactive waste drums before compaction in stainless steel containers. The whole monitoring system is composed of eight measurement stations which will be described in this paper. The main measurement stations $n^{\circ} 1,3$ and 7 are needed for criticality control. Before fuel element shearing for dissolution, station $n^{\circ} 1$ allows determining the burnup of the irradiated fuel by gamma-ray spectrometry with HP Ge (high purity germanium) detectors. The burn-up is correlated to the ${ }^{137} \mathrm{Cs}$ and ${ }^{134} \mathrm{Cs}$ gamma emission rates. The fuel maximal mass which can be loaded in one bucket of the dissolver is estimated from the lowest burn-up fraction of the fuel element. Station $n^{\circ} 3$ is dedicated to the control of the correct fuel dissolution, which is performed with a ${ }^{137} \mathrm{Cs}$ gamma ray measurement with a HP Ge detector. Station $n^{\circ} 7$ allows estimating the residual fissile mass in the drums filled with the metallic residues, especially the hulls, from passive neutron counting (spontaneous fission and alpha-n reactions) and active interrogation (fission prompt neutrons induced by a pulsed neutron generator) with proportional ${ }^{3} \mathrm{He}$ detectors.

So far, large campaigns of reprocessing of the UOX fuels with a burn-up rate up to $60 \mathrm{GWd} / \mathrm{t}$ have been performed at AREVA/La Hague. This paper presents a brief overview of the current status of the nuclear measurement stations.
\end{abstract}

Index Terms - Passive and active nuclear measurements Gamma-ray spectrometry, gamma-ray transmission, Passive and active neutron measurements.

\section{INTRODUCTION}

Manuscript submitted on June 2015. This work is supported by AREVA NC and CEA.

Cyrille Eleon, Christian Passard, Nicolas Hupont, Nicolas Estre, Olivier Gueton and François Brunner are with the CEA, DEN, Cadarache, Nuclear Measurement Laboratory, F-13108 Saint-Paul-lez-Durance, France (telephone: +33 442-256-130, e-mail: cyrille.eleon@cea.fr).

Marc Batifol, Philippe Doumerc, Thierry Dupuy, Benjamin Battel and Jean Christophe Vandamme with the AREVA NC, La Hague.

Gabriele Grassi is with the AREVA NC, La Defense.
The reprocessing plants (UP3 and UP2 800, AREVA $1 \mathrm{NC} / \mathrm{La}$ Hague) are dedicated to the Uranium Oxide (UOX) fuels reprocessing issue for the Pressurized Water Reactor (PWR) and the Boiling-Water-Reactor (BWR). The recycling process is composed of the fuel element shearing, the dissolution by nitric acid inside the dissolver, the uranium and plutonium separation, the vitrification of fission products and minor actinides, and the structure wastes conditioning (empty hulls, grids and end pieces) [1]. Eight nuclear measurement stations, based on the gamma-ray spectrometry, passive and active neutron measurement and gamma-ray transmission, contribute to the criticality-safety control, the online process monitoring and the determination of residual masses and activities within the hulls drums.

The measurement stations $1,2,3$ and 7 are crucial for criticality-safety control and for determination of the residual fissile mass. The main objectives of the station 1 are to check the burn-up of the fuel elements and to determine the maximal fuel mass which can be loaded in one bucket of the dissolver before fuel element shearing for dissolution. The goal of the station 3 is to measure the undissolved fuel fraction in one bucket. The stations 1 and 3 exploit the correlation between the burn-up and the ${ }^{137} \mathrm{Cs}$ and ${ }^{134} \mathrm{Cs}$ gamma emission rates. The ${ }^{137} \mathrm{Cs}$ and ${ }^{134} \mathrm{Cs}$ gamma emission rates are estimated by gamma-ray spectrometry with HP Ge detectors.

The station 1 also uses the correlation between the neutron emission rate and the burn-up [2]. The measurement is based on the passive neutron counting [2] (essentially due to the spontaneous fission of the ${ }^{244} \mathrm{Cm}$ ) with fission chambers.

The station 2 contributes to the shearing hopper control and the unblocking control of the dissolver chute by using gammaray passive method. It also allows inspecting the feeding hopper and the top of part of bucket immersed in the nitric acid from gamma-ray transmission measurement.

The station 7 estimates the residual fissile mass in the drums. It also allows estimating the residual alpha activity, residual beta-gamma activity and the uranium and plutonium masses.

The station 7 performs the measurement of the fission prompt neutrons [3] induced by a pulsed neutron generator and the passive neutron counting due to spontaneous fission and alpha-n reactions to determine the residual fissile mass. The neutron detection is realized with proportional ${ }^{3} \mathrm{He}$ detectors. The measurement stations 4,5 , and 6 contribute to online process monitoring such as the unloading control of the bucket, the non-jamming control of the hulls rinser feeding 
chute, and the control of the drum filling level, respectively. As for the station 2, these measurement stations are mainly based on the $1173 \mathrm{keV}$ and $1332 \mathrm{keV}$ energy gamma-ray transmission measurements from ${ }^{60} \mathrm{Co}$ sources and ionization chambers or the gamma-ray dose rate measurements from ionization chambers.

The stations 1,3 and 7 needed for criticality-safety assessment are described in Sections III, IV and V, respectively. The station 2 also required for criticality-safety assessment and the stations 4, 5 and 6 involved for on-line process control are briefly presented in Section VI.

The measurement station 8 is based on the fission delayed neutrons measurement induced by a ${ }^{252} \mathrm{Cf}$ source to estimate the residual plutonium mass deposited at the bottom of the vessels. This station only dedicated for the reprocessing of the Mixed Oxide fuels (MOX) will not be described in this paper.

\section{THE PROCESS NUCLEAR MONITORING}

Figure 1 illustrates the shearing-dissolution process and the different locations of the measurement stations. Before shearing-dissolution, the burn-up of the fuel elements are estimated by the station 1 and compared to a reference value extracted from the identification files of each fuel element. The shearing of the fuel element is carried out with a system composed of a blade and an anvil-blade, as described in Figure 2. In addition, the maximal mass which can be loaded in a bucket is determined using the burn-up of the least-irradiated fraction of the fuel, which is obtained by the station 1 . A dissolver is used for the fuel element reprocessing. It is composed of 12 buckets (see. Figure 3). The station 2 carries out the blocking control of the shearing hopper, the dissolver chute and the feeding hopper. The hulls fall down inside the bucket in position 1 (see. Figure 1) and are immersed in the nitric acid in order to extract the uranium, the plutonium, the minor actinides and the fission products. The end-pieces are also rinsed with nitric acid and water as illustrated in Figure 1. The dissolution process is going on when the bucket is in the positions 12, 11 and 10 as presented in Figure 1. Station 3 allows estimating the undissolved fuel fraction when the bucket is in position 9. The bucket is discharged from the position 7 towards the hulls rinser. The unloading control of the bucket is carried out from the station 4 and the blocking control of the hulls rinser chute is performed by the station 5 . The drum is filled with the hulls and end-pieces after dissolution and rinsing process. The station 6 is dedicated to control the drum's filling level with the hulls and end-pieces. The station 7 measures the residual fissile masses and activities in the drums from passive and active neutron methods [2] [3] before extraction toward the compaction station [4] in order to reduce the volume of the structure wastes by a factor of 5 .

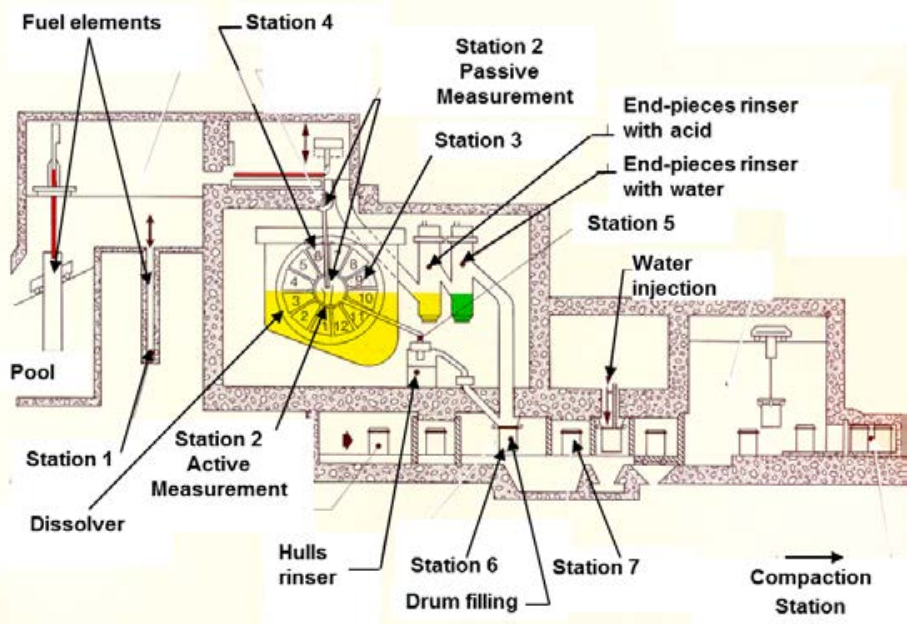

Fig. 1. Schematic principle of the process nuclear monitoring

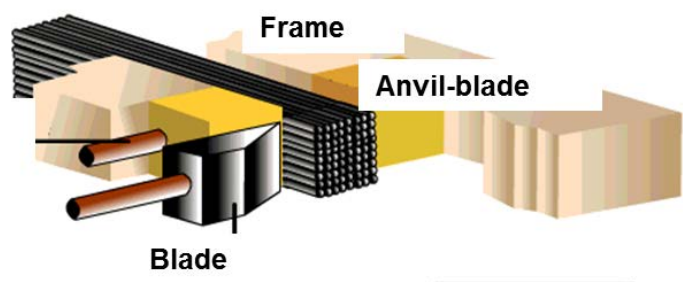

$\downarrow$ Dissolver

Fig. 2. Schematic principle of the shearing set-up.

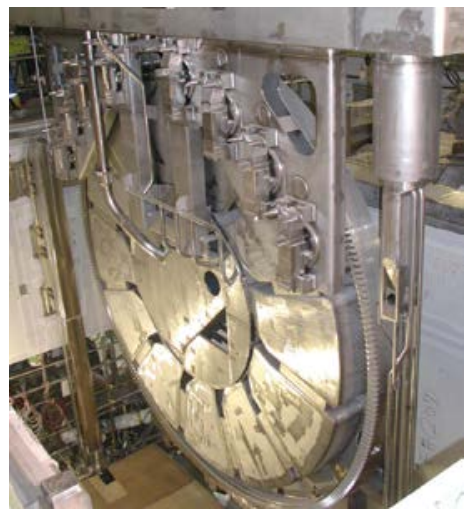

Fig. 3. Dissolver used for the fuel element reprocessing. The dissolver is constituted of 12 buckets.

\section{BURN-UP MEASUREMENT}

Figure 4 presents the station 1 which includes burn-up cavity, two HP Ge gamma-ray coaxial detectors and collimation setup.

A scanning system is used to carry out measurement on the total active length of the fuel assemblies (around $360 \mathrm{~cm}$ for the 900 MWe and around $420 \mathrm{~cm}$ for the 1300 MWe $17 \times 17$ PWR). This scanning system also allows obtaining the activity axial profile of the fuel element. In the axial plan, the collimation set-up allows observing a thin part of the fuel element and, in the radial plan the totality of the fuel assembly is analysed, as presented in Figure 4. The collimation aperture is precisely calculated according to the burn-up rate (BU), the 
cooling time (CT) and the initial ${ }^{235} \mathrm{U}$ enrichment given for each fuel assembly. In fact, a relation between the different parameters of the fuel assemblies and the aperture of the collimation was established to obtain a total gamma count rate inferior to 10000 c.s ${ }^{-1}$ which limits the count losses by pile-up and dead time. In addition, a polyethylene shell is also used to protect the HP Ge detectors from the direct neutron emission. The station 1 is also composed of two ${ }^{235} \mathrm{U}$ fission chambers in order to obtain the total neutron count rate due to the spontaneous fissions (the five principal neutron emitters are ${ }^{244} \mathrm{Cm},{ }^{242} \mathrm{Cm},{ }^{242} \mathrm{Pu},{ }^{240} \mathrm{Pu}$, and $\left.{ }^{238} \mathrm{Pu}\right)$ and the alpha-n reactions with oxygen. For the neutron measurements, the setup is made of a polyethylene $\left(\mathrm{CH}_{2}\right)$ and cadmium $(\mathrm{Cd})$ block surrounding the fission chamber. In addition, a lead shell is used to protect the neutron detectors from the gamma-ray emission.

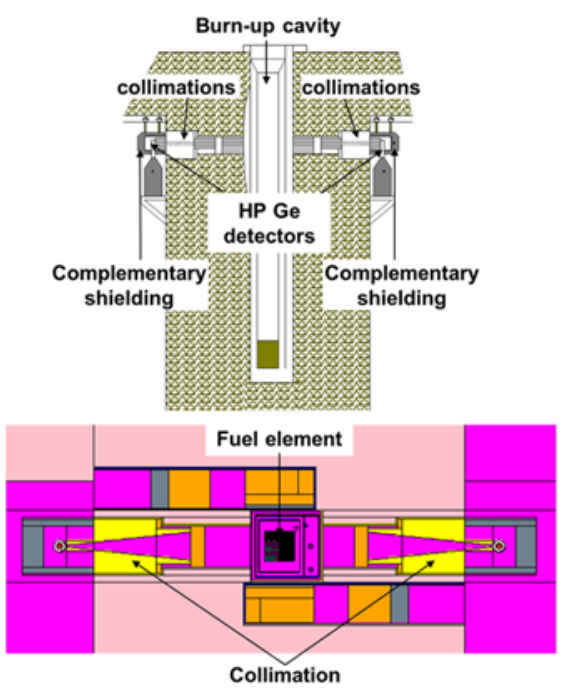

Fig. 4. Schematic principle of the station 1 (above: the axial plan is represented) and MCNP [6] numerical model (below: the radial plan is illustrated) used to assess performance for the

burn-up rate determination from gamma-ray activity measurement. Note that the neutron measurement set-up is not shown in this figure.

The burn-up is linearly dependent to the ${ }^{137} \mathrm{Cs}$ activity and to the ${ }^{134} \mathrm{Cs} /{ }^{137} \mathrm{Cs}$ activity ratio [5]. The burn-up to the power four is linearly dependent according to the neutron emission [2]. Consequently, three methods are applied to evaluate the burnup rate. The measurements of the ${ }^{137} \mathrm{Cs}\left(\mathrm{T}_{1 / 2}=30.15\right.$ years $)$ activity, of the ${ }^{134} \mathrm{Cs}$ activity $\left(\mathrm{T}_{1 / 2}=2.06\right.$ years) and of the total neutron count rate mainly due to the spontaneous fission of ${ }^{244} \mathrm{Cm}\left(\mathrm{T}_{1 / 2}=18.10\right.$ years$)$ allow to assess the burn-up of the irradiated fuel.

The ${ }^{134} \mathrm{Cs} /{ }^{137} \mathrm{Cs}$ activity ratio measurement is not affected by the geometry parameters such as the HP Ge position and the fuel assembly position and geometry compared to the absolute measurement of the ${ }^{137} \mathrm{Cs}$ activity which is strongly impacted. Therefore, it is considered as the reference method for the reprocessing of the PWR assemblies.

The gamma-ray measurement allows estimating the activity for the first rows fuel rods because of the strong selfabsorption. For the BWR, the initial ${ }^{235} \mathrm{U}$ enrichment can depend of the fuel rod position and the neutron flux during irradiation is not uniform [2]. In this case, the neutron measurement can give better results.

\section{DISSOLUTION CONTROL}

Figure 5 illustrates the station 3 for dissolution control. This station is composed of a HP Ge gamma-ray coaxial detector of type $n$ with a relative efficiency of $10 \%$, mobile and fixed shield and a collimator in order to measure the gamma-ray ${ }^{137} \mathrm{Cs}$ activity from the bucket. The thickness of the mobile shield is adjusted according to the gamma-ray total count rate from the residual fuel and the hulls and, consequently to the burn-up rate and cooling time of the reprocessed assembly.

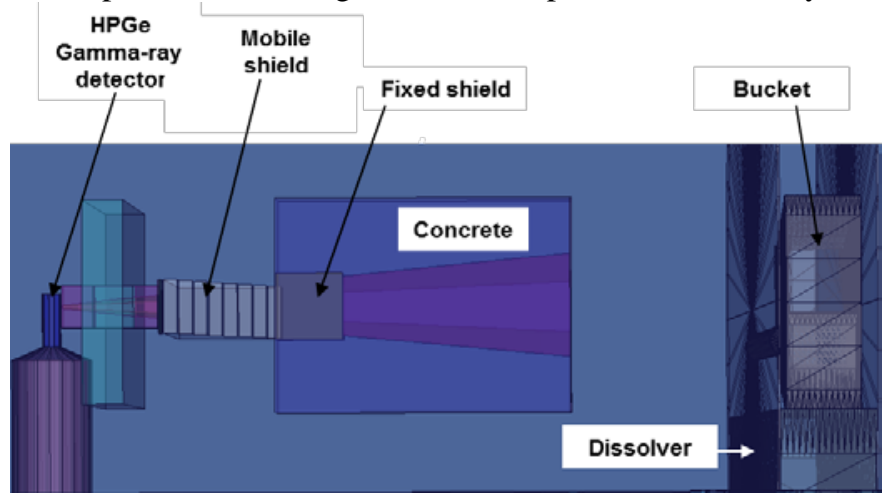

Fig. 5. MCNP numerical model for the performance assessment of the station 3 .

The residual mass of uranium is dependent on the gamma-ray activity of the ${ }^{137} \mathrm{Cs}$. Therefore, this station allows determining the undissolved fuel rate defined as the ratio between the raised uranium residual mass of two times the ${ }^{137} \mathrm{Cs}$ activity statistical measurement uncertainty and the initial mass of uranium loaded in the bucket.

\section{MEASUREMENT OF THE RESIDUAL MASSES AND ACTIVITIES INSIDE THE DRUMS.}

The main objective of the station 7 (see Figure 6) is to estimate the residual fissile mass inside the drums and also to contribute to the determination of the residual total alpha activity, the residual total beta-gamma activity, the uranium and plutonium masses. Consequently, two levels of data interpretation are operated by using an algorithm implanted at AREVA NC /La Hague: The first level is only based on the experimental results obtained with the active neutron method; the second level takes into account the experimental results of both passive and active neutron methods with the knowledge of the drum content.

Note that the algorithm takes into account the calculation data from CESAR depletion code [7] and correlations between the different physical parameters of the assemblies and activities.

The station 7 allows to measure the prompt neutrons produced by ${ }^{235} \mathrm{U},{ }^{239} \mathrm{Pu}$ and ${ }^{241} \mathrm{Pu}$ thermal fissions (active neutron method: Differential Die Away Technique) [8]. Figure 6 shows that the station 7 is composed of a neutron generator and ${ }^{3} \mathrm{He}$ detectors. $14 \mathrm{MeV}$ neutrons are thermalized by the polyethylene blocks and the inspected drum filled with the hulls and end-pieces and produce thermal fission reactions inside the drum. The ${ }^{3} \mathrm{He}$ detection blocks are composed of $\mathrm{B}_{4} \mathrm{C}$ (boron carbide) and $\mathrm{Cd}$ (cadmium), in view to absorb the 
interrogating thermal neutron flux, and $\mathrm{CH}_{2}$ (polyethylene) in order to thermalize the fast neutron flux (average energy of $2 \mathrm{MeV}$ ) from fission reactions before detection by the ${ }^{3} \mathrm{He}$ neutron counters, as illustrated in Figure 6. A lead shielding is also used to minimize the gamma-ray dose on the ${ }^{3} \mathrm{He}$ neutron detectors (see Figure 6).

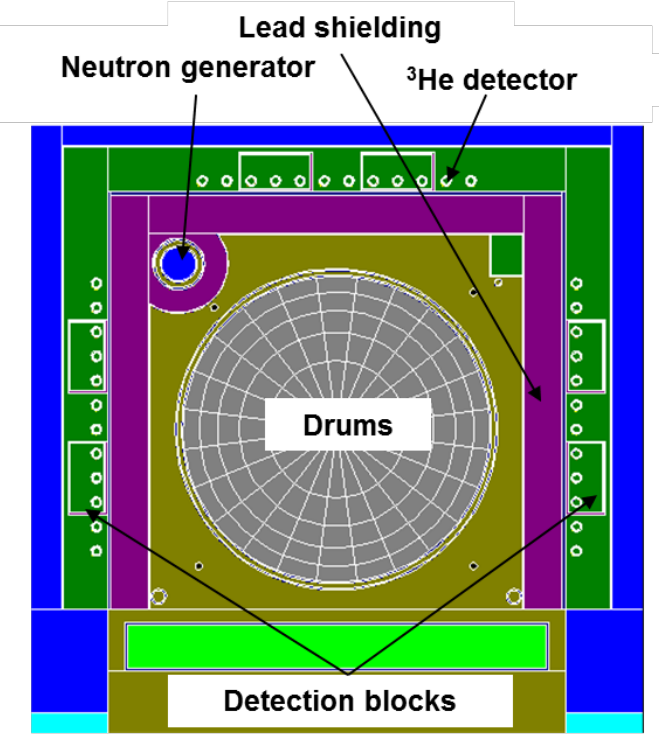

Fig. 6. MCNP numerical model for the performance assessment of the station 7

The residual fissile mass is determined from the useful signal amplitude (counts. $\mathrm{s}^{-1}$ ) and a calibration factor (g of fissile masse.counts ${ }^{-1} . \mathrm{s}$ ) obtained from a reference drum associated with MCNP simulation.

For the passive neutron method, the station 7 also allows to measure the total neutron count rate emitted by the drum coming from the spontaneous fissions and alpha-n reactions. The passive measurement contributes to the determination of the physical parameters of the drums mentioned above.

\section{SHEARING HOPPER, CHUTE AND FEEDING HOPPER CONTROLS AND ON-LINE PROCESS MONITORING}

The station 2 (see Figure 7) is based on a gamma-ray dose rate measurement (passive method) for the shearing hopper and the chute controls (see MCNP model presented in Figure 7). In fact, the useful signal of the upper ionization chamber (see M5 ionization chamber illustrated in Figure 7) is directly compared to a threshold determined from background measurement in order to detect a potential blocking of the shearing hopper by the hulls. In addition, a comparison between the useful signal intensity delivered by the upper ionization chamber and the useful signal intensity given by the lower ionization chamber (M6 ionization chamber illustrated in Figure 7) is also used to detect a possible obstruction of the dissolver chute by the hulls between the two ionization chambers.

Moreover, an active method based on a gamma-ray transmission measurement from two ${ }^{60} \mathrm{Co}$ sources with an activity of $300 \mathrm{Ci}$ and ionization chambers for detection allows controlling the feeding hopper and the top of the part of the bucket immersed in the nitric acid for fuel dissolution.
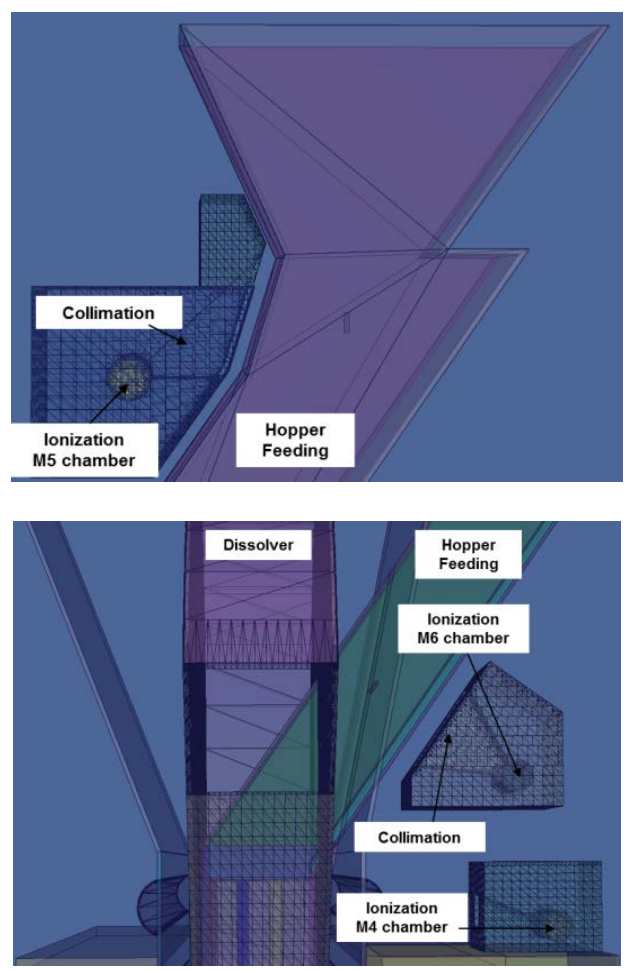

Fig 7. MCNP numerical model of the station 2 used for the performance assessment for the shearing hopper (above) and chute control (below) by gamma-ray passive method. The gamma-ray active method is not illustrated in this Figure. Note that the ionization M6 chamber is used to control the lower part of the chute.

For on-line process monitoring, the stations 4,5 and 6 (see Figure 8) use the same measurement principles described above (gamma-ray dose rate and gamma-ray transmission measurements) for the unloading control of the bucket, the non-jamming control of the hulls rinser chute, and the control of the drum filling level, respectively.

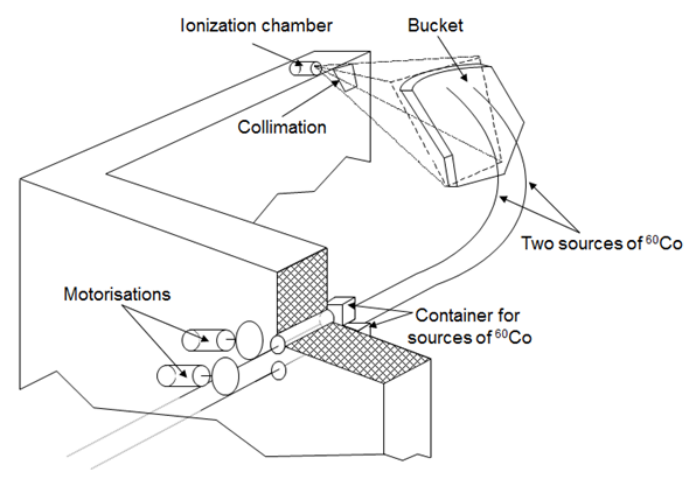



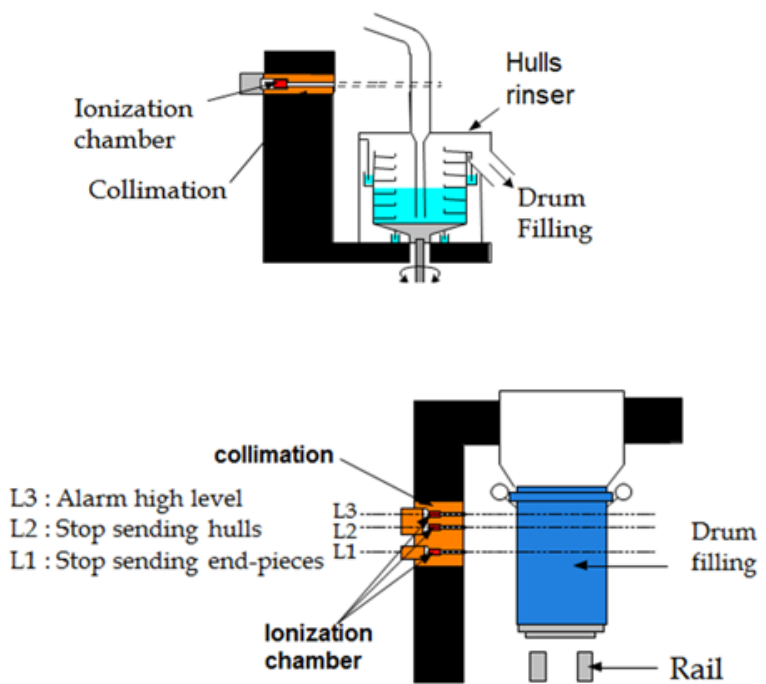

Fig 8. Schematic principle of the station 4 (first representation) based on the gamma-ray transmission measurement with two sources of ${ }^{60} \mathrm{Co}$ and ionization chamber, the stations 5 (second representation) and 6 (third representation) based on the gamma-ray dose rate measurement with ionization chambers.

\section{CONCLUSION}

Since 1990, the several measurement stations control all the process of the spent fuel reprocessing. The large campaigns of reprocessing of the UOX fuels with a burn-up rate up to $60 \mathrm{GWd} / \mathrm{t}$ realized at AREVA NC/La Hague and the MCNP models allow continually assessing the performance of the different measurement stations. Presently, the different stations are also studied in order to estimate the measurement performance for the reprocessing of high burn-up UOX fuels and MOX fuels.

\section{ACKNOWLEDGMENT}

This work is supported by AREVA-NC and CEA.

\section{REFERENCES}

[1] J. Chabert, Control and Command System for the process of spent fuel reprocessing. Instrumentation. Engineering BN3445, 1997

[2] D. Reilly, N. Ensslin, Hastings Smith Jr, Passive Non Destructive Assay of Nuclear Materials. Los Alamos National Laboratory, NUREG/CR-5550, 1991

[3] T. Gozani, Active Nondestructive Assay of Nuclear Materials, Principles and Applications, NUREG/CR-0602 SAI-MLM-2585, January 1981

[4] H. Toubon, T. Gain, B. Perot, A. Lyoussi, A.C. Raoux, G. Melhman, X. de Brimont, P.A. Tulle, Method for ascertaining the characteristics of the radiological content of canister of compacted hull and nozzle waste resulting from reprocessing at AREVA NC/La Hague of irradiated fuel assemblies from light-water reactors, October 2-4, 2000, MONTPELLIER (France)
[5] P. Bernard, G. Lamarque, G. Le Guillou, L. MartinDeidier, J. Chabert, W. Fournier, M. Laloe, Process Nuclear Monitoring at UP3. RECOD 91 Conference, April 14-18, 1991, SENDAI (Japon)

[6] MCNPX ${ }^{\mathrm{TM}}$ USER'S MANUAL Version 2.4.0, LA-CP-02408, Los Alamos, USA, 2002

[7] J-M. Vidal, R. Eschbach, A. Launay, C. Binet, J-F. Thro, CESAR5.3: An industrial tool for nuclear fuel and waste characterization with associated qualification, WM2012 Conference, February 26-March, 2012, Phoenix, Arizona (USA)

[8] W.E. Kunz, J.D. Atencio, J.T. Caldwell, A 1 nCi/g sensitivity transuranic waste assay system using pulsed neutron interrogation, INMM Annual meeting, Palm Beach, Florida, LA-UR-90-1794, CONF-800655-4, 1980. 